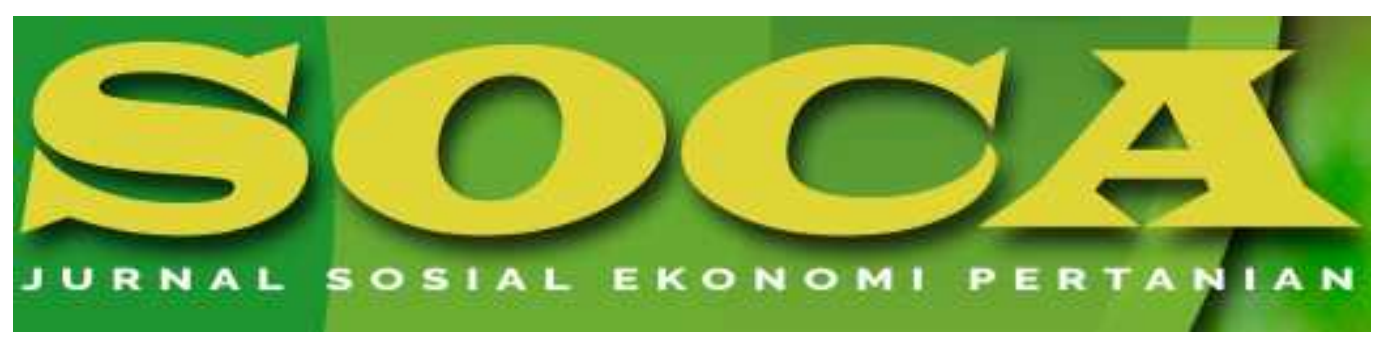

https://ojs.unud.ac.id/index.php/soca

\title{
PRODUK SAMPING TANAMAN UBIKAYU SEBAGAI POTENSI BIOEKONOMI UNTUK PERTANIAN MASA DEPAN
}

\author{
Fahrur Rozi ${ }^{1}$ dan Agnes Quartina Pudjiastuti ${ }^{2}$ \\ ${ }^{1}$ Balai Penelitian Kacang-kacangan dan Umbi-umbian Malang \\ 2Program Studi Magister Ekonomi Pertanian, Sekolah Pascasarjana, Universitas Tribhuwana \\ Tunggadewi \\ Email: agnespudjiastuti@yahoo.com, Telepon/Hp: 081555761529
}

\begin{tabular}{l} 
Kata Kunci: \\
limbah, \\
ubikayu, nilai \\
ekonomi, \\
bioekonomi \\
\hline
\end{tabular}

\begin{abstract}
Abstrak
Potensi dan peluang pengembangan ubikayu masih sangat terbuka luas sejalan dengan berkembangnya perusahaan-perusahaan bidang peternakan, pangan olahan, dan industri lainnya. Nilai tambah komoditas ubikayu yang dihasilkan dari pengembangan industri hilir (produk olahan) jauh lebih tinggi dari industri hulu (produk primer), sehingga paradigma pembangunan di sektor pertanian ke depan seharusnya diarahkan pada perluasan produk termasuk limbahnya. Penelitian ini bertujuan mengkaji nilai ekonomi ubikayu sebagai tanaman masa depan dari hasil langsung maupun hasil samping serta strategi pengembangannya. Data dikumpulkan dari petani, peternak, dan pengusaha tepung tapioka berskala kecil. Analisis SWOT digunakan untuk menentukan strategi pengembangan yang relevan. Hasil analisis menunjukkan bahwa ubikayu memiliki potensi yang semakin penting di masa mendatang terutama sebagai bahan baku industri pangan dan pakan. Dalam jangka pendek strategi pengembangan ubikayu sebagai bahan baku industri yang dilakukan adalah penggunaan teknologi baru berupa varietas dan teknik budidaya pengaturan tanam. Potensi nilai ekonomi ubikayu relatif tinggi ditinjau dari aspek usahatani, bahan baku pangan, pakan dan industri. Potensi ini, selain yang langsung dari hasil utama, juga produk samping yang selama ini yaitu 29,7\% dari hasil utama ubikayu. Potensi produk samping ini belum digunakan secara optimal dan merupakan nilai bioekonomi berupa biomassa yang dapat menunjang pertanian integrasi di masa mendatang
\end{abstract}




\section{SIDE PRODUCTS OF CASSAVA CROP AS BIOECONOMY POTENTIAL FOR FUTURE AGRICULTURE}

\begin{tabular}{l}
\hline Keywords: by- \\
products, \\
cassava, \\
economic value, \\
bioeconomy \\
\hline
\end{tabular}

\begin{abstract}
Abstrak
Potential and opportunities for cassava development are still very broad along with development of companies in livestock, processed food, and other industries. Added value of cassava commodities resulting from development of downstream industries (processed products) is far higher than upstream industries (primary products), so that development paradigm in agriculture sector in future should be directed towards product expansion including its waste. This study aims to examine the economic value of cassava as a future crop from direct as well as by-products and their development strategies. Data was collected from small-scale tapioca flour farmers, ranchers and entrepreneurs. SWOT analysis was used to determine relevant development strategies. Analysis shows that cassava has an potential, especially as a raw material for food and feed industry. In short term, developing cassava strategy as an industrial raw material is to use new technologies i.e. varieties and cultivation techniques for planting arrangements. Cassava potential economic value is relatively high in terms of farming aspects, food raw materials, feed and industry. This potential, apart from main product, is also by-product that has been neglected at 29.7\% of cassava main value. By-products potensial has not been used optimally and a bioeconomic value of biomass that can support integrated agriculture in the future.
\end{abstract}

How to Cite (APA 6 ${ }^{\text {th }}$ Style):

Rozi, F., \& Pudjiastuti, A. Q. (2019). Produk Samping Tanaman Ubikayu Sebagai Potensi Bioekonomi Untuk Pertanian Masa Depan. SOCA: Jurnal Sosial Ekonomi Pertanian, 13(3), 433-446. https://doi.org/https://doi.org/10.24843/SOCA.2019.v13.i03.p12

\section{PENDAHULUAN}

Pertanian masa depan adalah pertanian modern, yang dalam perspektif bioekonomi, tidak mengenal adanya produksi limbah tak termanfaatkan. Oleh karena itu, biomassa pertanian harus dapat diolah untuk menghasilkan produk bernilai tambah secara ekonomi. Berkaitan dengan hal tersebut, ubikayu mempunyai produk samping limbah yang belum termanfaatkan dan dapat mendukung pertanian di masa depan. Menyadari nilai tambah komoditas ubikayu yang diperoleh dari pengembangan industri hilir atau produk olahan jauh lebih tinggi dari industri hulu atau produk primer, maka paradigma pembangunan pertanian masa depan seharusnya diarahkan ke pengembangan produk (product 
development). Peningkatan nilai komoditas melalui pengembangan industri dalam hal ini adalah agroindustri yang mengolah hasil pertanian primer menjadi produk olahan. Produk olahan yang dimaksud dapat berupa produk antara (intermediate product) maupun produk akhir (final product) yang berdaya saing (Simatupang, 2006). Hasil analisis di Industri Tepung Tapioka Rakyat (Ittara) menunjukkan bahwa nilai tambah pengolahan ubikayu menjadi tepung tapioka adalah sebesar Rp. 57,91 per kilogram ubikayu (Asnawi, 2003), sedangkan di Kabupaten Trenggalek Rp. 95,68 per kilogram ubikayu (Rozi dan Heriyanto, 2007). Damarjati (2011) mengemukakan bahwa agroindustri adalah sektor yang mampu menghasilkan nilai tambah untuk produk pertanian. Dengan demikian, ada keterkaitan langsung antara agroindustri dan pertanian primer, di mana industri ini akan mentransformasi produk primer pertanian menjadi barang setengah jadi (intermediate goods) maupun barang konsumsi (final goods). Oleh karena sektor pertanian primer sangat tergantung pada industri, sistem perdagangan dan distribusi input produksi, maka kinerja pertanian dan industri ini akan menentukan pola pengembangan agroindustri selanjutnya.

Berdasarkan Strategi Induk Pembangunan Pertanian (SIPP) 2013-2045 (Kementan 2013), ada dua teknologi utama yang dipersiapkan untuk pengembangan agroindustri ubikayu. Pertama, teknologi tanaman ubikayu integrasi dengan ternak, teknologi yang menghasilkan biomassa tinggi untuk kebutuhan pakan. Permasalahan kompetisi terhadap sumberdaya alam yang mungkin timbul dari intensifikasi pemanfaatan lahan dapat teratasi dengan cara integrasi seperti ini. Cara ini mampu menyediakan kebutuhan biomassa untuk kebutuhan pangan, pakan, dan juga sebagai bahan baku industri. Kedua, teknologi tanaman ubikayu integrasi dengan energi, yang menghasilkan biomassa tinggi untuk kebutuhan energi. Teknologi ini disiapkan terutama untuk usahatani ubikayu yang memanfaatkan lahan marjinal dan suboptimal. Optimasi pemanfaatan lahan tersebut akan meningkatkan produktivitas biomassa tanaman ubikayu sehingga akan berfungsi sebagai lahan penyedia bahan baku bioindustri non pangan.

Sebenarnya, banyak teknologi ubikayu yang telah tersedia untuk tujuan industri. Namun teknologi tersebut belum dimanfaatkan oleh pengguna (petani) yang sesuai dengan keinginan industri. Disamping itu, tidak banyak informasi mengenai preferensi biomassa dari tanaman ubikayu yang dibutuhkan sebagai bahan baku oleh industri. Dengan demikian, diperlukan informasi mengenai potensi dan permasalahan tanaman ubikayu yang terkait dengan bioindustri.

Kebutuhan ubikayu sebagai bahan baku untuk pangan maupun non pangan semakin tinggi di masa mendatang. Permintaan yang tinggi perlu diimbangi dengan pasokan yang memadai dari produsen ubikayu (petani). Produksi ubikayu di Indonesia selama tahun 2012-2016 tercatat mengalami penurunan rata-rata 3,73\% per tahun, di mana kontribusi penurunan yang lebih besar berasal dari luar Pulau Jawa. Perkembangan ubikayu di luar Pulau Jawa mengalami penurunan lebih besar dibanding Pulau Jawa yaitu 4,21\% per tahun dibanding 3,05\% per tahun (Pusdatin, 2016). Kesenjangan antara produksi dan konsumsi ubikayu akan semakin besar seiring dengan pertumbuhan penduduk dan industri berbasis ubikayu. Sementara ini usahatani ubikayu banyak menggunakan input produksi yang berasal dari sumberdaya fosil (kimiawi). Dengan kelangkaan dan hampir punahnya sumberdaya fosil tersebut, diperlukan pengalihan kepada sumberdaya baru dan terbarukan yaitu sumberdaya hayati (biomassa). Hingga saat ini, belum banyak informasi 
tentang permasalahan penggunaan sumberdaya hayati tanaman ubikayu untuk tujuan bioindustri, sehingga untuk membangun fondasi sistim pertanian bioindustri diperlukan informasi mengenai potensi dan kendala dari sumberdaya hayati usahatani komoditas ini.

Potensi dan peluang usahatani ubikayu masih terbuka luas seiring berkembangnya perusahaan peternakan, pangan olahan, dan industri lainnya seperti alkohol, sorbitol, fruktosa dan lainnya. Di masa depan, industri plastik akan menggunakan ubikayu sebagai bahan baku. Pengolahan produk berbahan baku ubikayu juga didukung oleh berbagai teknologi hasil penelitian seperti pengolahan untuk pangan dan industri lainnya.

Penelitian ini bertujuan menganalisis nilai ekonomi ubikayu sebagai tanaman masa depan dari hasil langsung maupun hasil samping serta strategi pengembangannya.

\section{METODE PENELITIAN}

Penelitian ini dilakukan di daerah yang representatip potensi untuk pengembangan tanaman ubi kayu dalam mendukung bioindustri di Jawa Timur yaitu Kabupaten Kediri. Wilayah ini memiliki petani ubikayu, peternak (pengguna pakan) dan pengusaha tepung tapioka yang berskala kecil.

Metode survei digunakan dalam penelitian ini untuk mengidentifikasi potensi, peluang dan permasalahan pengembangan tanaman ubi kayu dalam mendukung bioindustri. Survei dilakukan melalui pendekatan pemahaman pedesaan secara cepat dan dengan partisipasi masyarakat, atau sering dikenal sebagai Participatory Rural Appraisal (PRA) (Toness, 2001; Beebe, 2014). Pelaksanaan PRA bersifat terbuka dan mendalam dengan menggunakan diskusi kelompok dan melibatkan semua 'key persons' yang terkait dengan topik permasalahan. Hal ini dilakukan selain memberikan pemahaman pengembangan tanaman ubi kayu berbasis bioindustri juga mengidentifikasi masalah di lapang. Informasi digali dari responden kunci (key person) yaitu 5 petani, 5 peternak, dan 5 pengusaha berskala kecil yang mengolah ubikayu menjadi tepung tapioka. Kelengkapan informasi dari hulu sampai hilir produk ubikayu menjadi sasaran survei agar dapat menggambarkan tujuan penelitian.

Pendekatan yang ditempuh dalam penelitian untuk mengetahui pengembangan tanaman ubikayu mendukung bioindustri adalah:

- Menghimpun data/informasi, baik primer maupun sekunder mengenai potensi dan permasalahan produksi tanaman ubikayu untuk tujuan bioindustri yang dilakukan oleh pelaku usaha baik petani maupun industri.

- Melakukan survei lapang ke industri yang berbahan baku biomassa dari tanaman ubikayu. Tujuannya adalah untuk mengetahui preferensi kebutuhan bahan baku dalam menghasilkan bioproduk dari industri tersebut.

- Informasi potensi dan permasalahan produksi tanaman ubikayu yang telah diperoleh diterjemahkan ke dalam 4 (empat) komponen SWOT yaitu kekuatan, kelemahan, peluang, dan ancaman. Dengan teridentifikasinya 4 faktor tersebut, dapat disusun strategi pengembangan produksi tanaman ubikayu dalam mendukung bioindustri. 
Analisis SWOT digunakan untuk merumuskan peta pengembangan dan strategi untuk mencapainya. Untuk mengetahui potensi nilai ekonomi dari tanaman ubikayu untuk tujuan bioindustri dengan menghitung total nilai ekonomi dari biomassa. Analisis SWOT merupakan aktivitas identifikasi berbagai faktor secara sistematis untuk merumuskan strategi. Analisis didasarkan pada logika memaksimumkan kekuatan (strengths) dan peluang (opportunities), namun sekaligus meminimalkan kelemahan (weakness) dan ancaman (threats). Upaya memecahkan permasalahan pengembangan tanaman ubi kayu dalam mendukung bioindustri dengan menggunakan strategi untuk mencapainya. Menurut Rangkuti (2001), strategi yang diperoleh dari analisis SWOT merupakan alat untuk mencapai tujuan, program tindak lanjut dan prioritas alokasi sumberdaya. Strategi yang efektif dapat dicapai melalui analisis lingkungan sebagai dasar identifikasi kekuatan dan kelemahan serta peluang dan ancaman. Matriks SWOT menggambarkan secara jelas bagaimana kekuatan dan kelemahan digunakan untuk mengantisipasi peluang dan ancaman eksternal bioindustri. Rumusan hasil analisis ini meliputi empat alternatif strategi yaitu SO, WO, ST dan WT. Strategi SO merupakan strategi memanfaatkan kekuatan bioindustri ubikayu untuk memperoleh peluang yang ada. Strategi WO merupakan strategi untuk mengatasi kelemahan bioindustri ubikayu dengan peluang yang dimiliki. Strategi ST menggunakan kekuatan bioindustri ubikayu untuk menghadapi ancaman dari luar. Strategi WT difokuskan pada kegiatan yang bersifat defensif dan meminimalkan kelemahan yang ada serta menghindari ancaman. Data yang dikumpulkan meliputi: (1) faktor pendukung (kekuatan), kekurangan/ kelemahan penggunaan input dari sumberdaya hayati usahatani, dan peluang, hambatan berusaha komoditas ubikayu dengan input sumberdaya hayati; (2) Nilai ekonomi produk dari sumberdaya hayati atau biomassa (use values, non use values); (3) Kebutuhan dan preferensi biomassa oleh industri sebagai bahan baku; (4) Efisiensi penggunaan input produksi (sumberdaya) untuk usahatani ubikayu.

Potensi nilai ekonomi dari tanaman ubikayu untuk tujuan bioindustri diidentifikasi dengan menghitung total nilai ekonomi dari biomassa. Menurut Suparmoko dan Maria (2000), nilai sumberdaya alam dikelompokkan menjadi nilai atas dasar penggunaan (instrumental value) dan nilai tanpa penggunaan secara intrinsik yang melekat dalam aset sumberdaya alam (intrinsic value). Menurut penggunaannya, nilai ekonomi suatu sumberdaya digolongkan menjadi nilai atas dasar penggunaan (use values) dan nilai yang terkandung di dalamnya atau nilai intrinsik (non use values). Nilai penggunaan sumberdaya ada yang bersifat langsung (direct use values) dan tidak langsung (indirect use values) serta nilai pilihan (option values). Nilai penggunaan tidak langsung (non use values) dibedakan lagi menjadi nilai keberadaan (existence values) dan nilai warisan (bequest values). Nilai ekonomi total (NET) atau total economic value (TEV) merupakan penjumlahan nilai atas dasar penggunaan langsung dan tidak langsung (Pearce dan Turner, 1991; Munasinghe, 1993; Pearce dan Moran, 1994). NET dapat ditulis dengan persamaan matematis sebagai berikut:

$$
\begin{array}{ll}
\mathrm{NET} & =\mathrm{NP}+\mathrm{NI} \\
\mathrm{NP} & =\mathrm{NPL}+\mathrm{NPTL}+\mathrm{NPi} \\
\mathrm{NI} & =\mathrm{NK}+\mathrm{NW}
\end{array}
$$


$\mathrm{NET}=\mathrm{NP}+\mathrm{NI}=(\mathrm{NPL}+\mathrm{NPTL}+\mathrm{NPi})+(\mathrm{NK}+\mathrm{NW})$

di mana:

NET = Nilai Ekonomi Total (total economic value/TEV)

NP = Nilai Penggunaan (Use Values/UV)

NI = Nilai Intrinsik (Non Use Value)

NPL = Nilai Penggunaan Langsung (Direct Use Value/DUV)

NPTL = Nilai Penggunaan Tidak Langsung (Inderect Use Value)

NPi = Nilai Pilihan (Option Value)

$\mathrm{NK}=$ Nilai Keberadaan (Existence Value)

$\mathrm{NW}=$ Nilai Warisan/Kebanggaan (Bequest Value)

\section{HASIL DAN PEMBAHASAN}

\section{Peran Ubikayu di Masa Mendatang}

Kebutuhan ubikayu sebagai bahan baku untuk pangan maupun non pangan semakin tinggi di masa mendatang akan berdampak pada aktivitas proses produksi dan pasca produksi.

\section{Proses produksi}

Permintaan ubikayu yang tinggi perlu diimbangi dengan pasokan yang kontinu oleh petani. Harga ubikayu basah di beberapa daerah di Jawa bertahan di tingkat Rp 800-900 per kg. Kenaikan harga ubikayu mendorong harga gaplek naik dari Rp 1200 per kg menjadi Rp 1900 per kg. Kenaikan harga ubikayu dan gaplek ini disebabkan oleh sulitnya memperoleh bahan baku. Anomali iklim pada awal tahun menyebabkan produksi ubikayu di sejumlah negara terganggu dan banyak ubikayu lokal yang dijual di pasar ekspor (Munthe BC, 2011).

Pengembangan produksi tanaman ubikayu akan menciptakan sistem industrial yang berdaya saing karena merupakan bahan baku yang murah, mudah ditanam, mempunyai daya tumbuh luas, baik di lahan subur maupun marjinal. Karakteristik ini memungkinkan produk ubikayu memiliki prospek untuk menciptakan kesempatan kerja dan peningkatan kesejahteraan petani. Namun kelembagaan penunjang sistem usahatani ubikayu untuk tujuan industri belum tertata dengan baik.

Pembangunan agroindustri ubikayu dapat dilakukan oleh industri rumah tangga berskala kecil hingga industri besar. Beberapa usaha berbahan baku biomassa dari ubikayu antara lain: industri chip, sawut atau gaplek berskala kecil dan menengah, dapat dibangun di daerah hulu. Industri ini dapat membangun kemitraan dengan petani sebagai produsen ubikayu. Di samping penggunaan pangan dan pakan, ubikayu dapat dikembangkan sebagai bahan baku bioetanol. Bioetanol adalah sebagai sumber energi alternatif bahan bakar selain premium dan dilakukan pada skala besar atau pabrik. Sistem usahatani ubikayu berbasis bioindustri akan berjalan jika diketahui faktor-faktor permasalahan dari sumberdaya dan kelembagaan pendukung industri teridentifikasi dengan jelas.

Belum banyak diketahui preferensi terhadap bahan baku yang dibutuhkan industri. Banyak varietas ubikayu mempunyai karakteristik dan spesifikasi yang cocok untuk industri, seperti ubikayu yang mempunyai rasa enak untuk pangan, 
ubikayu dengan biomassa banyak untuk pakan, ubikayu dengan kandungan pati yang tinggi untuk etanol, dan masih banyak karakteristik ubikayu lainnya yang belum teridentifikasi.

Dalam kurun waktu antara tahun 1978--2006; sekitar 10 varietas unggul ubikayu telah diluncurkan oleh pemerintah, yaitu: Adira-1, Adira-2, Adira-4, Malang-1, Malang-2, Darul hidayah, UJ-3, UJ-5, Malang-4, Malang-6 (Suhartina, 2005). Varietas unggul ubikayu tersebut pada umumnya disebarluaskan melalui permintaan Direktorat Perbenihan (Deptan). Pada tahun 2006, UPBS-Balitkabi telah mengirim pesanan stek BS ubikayu ke Direktorat Perbenihan (Deptan) sebanyak: 400 stek varietas unggul Adira-4, 300 stek varietas unggul Adira-1, 100 stek varietas unggul Malang-6 dan 200 stek varietas unggul UJ-5. Suhartina (2005) menyatakan bahwa tingkat hasil varietas unggul ubikayu yang telah dilepas pemerintah mampu mencapai > $30 \mathrm{t} \mathrm{ha}^{-1}$ (Adira-4; Malang-1, 2, 4, dan 6; Uj-3 dan 5). Oleh karena itu, upaya untuk memperbaiki proses produksi ubikayu dapat dilakukan dengan menanam varietas unggul tersebut. Selain untuk meningkatkan hasil dan pendapatan petani, varietas unggul juga dimaksudkan untuk meningkatkan produksi ubikayu secara nasional. Permasalahan mendasar yang muncul adalah (1) Varietas unggul mana yang diadopsi petani ubikayu; (2) Kendala apa yang dihadapi petani dalam menggunakan varietas unggul; (3) Pilihan karakter tanaman manakah yang digunakan petani sebagai sumber bibit; dan (4) Faktor-faktor apa yang menentukan petani dalam memilih komoditas atau varietas dalam berusahatani.

\section{Pasca Produksi}

Selama ini, usahatani umbi-umbian, khususnya ubikayu, belum mengimplementasikan konsep usaha yang efisien karena belum memanfaatkan potensi dan peluang secara optimal. Banyak manfaat dari limbah (biomassa) ubikayu, di antaranya dijadikan pakan inkonvensional (Chuzaemi, 2002). Menurut FAO dalam Anggraeny (2006), limbah untuk bahan pakan inkonvensional mempunyai karakteristik: (1) sebagai hasil akhir suatu produksi yang tidak dapat didaur ulang, (2) sebagai bahan organik berbentuk padat dan cairan, (3) nilai ekonominya lebih rendah dibanding biaya pengumpulan dan pemrosesan, (4) sebagai sumber fermentable carbohydrate, (5) limbah tanaman pangan bersifat bulky dengan kandungan serat kasar tinggi dan nitrogen rendah.

Potensi komoditas pangan yang dapat dikembangkan di Indonesia terutama di Pulau Jawa adalah singkong atau ubi kayu. Ubikayu merupakan salah satu tanaman pangan yang menjadi sumber pakan potensial untuk sapi potong karena hampir semua bagian tanaman maupun limbah agroindustrinya bermanfaat. Kulit luar ubikayu berpotensi untuk digunakan sebagai bahan pakan. Produksi ubikayu sebesar 18,9 juta ton per tahun akan menghasilkan limbah kulit dalam (berwarna putih) mencapai 1,5-2,8 juta ton dan limbah kulit luar (berwarna coklat) mencapai 0,04-0,09 juta ton.

\section{Manfaat Ekonomi Ubikayu}

Secara ekonomi, manfaat ubikayu baik produk maupun limbahnya saat ini dan di masa mendatang sangat ditentukan oleh harga dan permintaan di pasar dunia. Kebijakan pemerintah yang tepat atas komoditi pertanian akan berpengaruh positif terhadap neraca perdagangan (Pudjiastuti, et al., 2013; Pudjiastuti, 2014; 
Pudjiastuti and Kembauw, 2018) dan kesejahteraan masyarakat. Pengembangan komoditas ubikayu dan potensi ekonominya dijelaskan berikut ini.

\section{Pengembangan Komoditas Ubikayu}

Strategi pengembangan komoditas ubikayu dalam kajian ini ditetapkan dengan memetakan kekuatan, kelemahan, peluang dan ancaman. Hasil analisis penyusunan strategi (Tabel 1) menunjukkan bahwa pengembangan usahatani ubikayu untuk bahan baku industri ada di kuadran II, artinya arah pengembangan masih terdapat ancaman (T) di samping didukung oleh faktor kekuatan (S), sehingga menggali kekuatan yang dimiliki untuk mengatasi hambatan (ancaman) yang ada perlu menyusun strategi aplikatif.

Kekuatan yang dimiliki dalam perluasan manfaat ubikayu untuk bahan baku industri lebih dominan dibanding dengan kelemahan, sehingga kekuatan tersebut akan mampu menutupi kelemahan yang ada dan keadaan dalam lingkungan internal usahatani ubikayu mudah dikendalikan. Selain itu, pengembangan ubikayu untuk bahan baku industri juga menghadapi hambatan atau ancaman cukup besar. Implementasinya pelaku kebijakan harus mampu memanfaatkan kekuatan yang ada dalam menghadapi ancaman. Peta kekuatan dari masing-masing faktor disajikan di Gambar 1.

Tabel 1. Matrik Keterkaitan Analisis SWOT dalam Pengembangan Komoditas Ubikayu

\begin{tabular}{|c|c|c|c|c|c|c|c|c|}
\hline No & Faktor & $\mathrm{BF}(\%)$ & ND & NDB & NRK & NBK & TNB & $\sum \mathrm{TNB}$ \\
\hline & Strengths (S) & & & & & & & 3,9 \\
\hline 1 & Dapat dibuat beragam produk & 18,87 & 5 & 0,943 & 2,9 & 0,6 & 1,5 & \\
\hline 2 & Modal kecil & 3,77 & 5 & 0,189 & 2,6 & 0,1 & 0,3 & \\
\hline 3 & $\begin{array}{l}\text { Menghasilkan produk utama (pati) dan } \\
\text { ikutan (gamblong, kulit, bonggol dsb) }\end{array}$ & 1,89 & 5 & 0,094 & 2,5 & 0,0 & 0,1 & \\
\hline 4 & Terbentuknya kelembagaan (asosiasi pati) & 1,89 & 5 & 0,094 & 1,3 & 0,0 & 0,1 & \\
\hline 5 & Pengalaman membuat pati sudah lama & 16,98 & 4 & 0,679 & 2,2 & 0,4 & 1,1 & \\
\hline \multirow[t]{2}{*}{6} & $\begin{array}{l}\text { Terbangunnya kemitraan dengan produsen } \\
\text { dan pemasok bahan baku ubikayu }\end{array}$ & 11,32 & 5 & 0,566 & 1,8 & 0,2 & 0,8 & \\
\hline & Weaknesses (W) & & & & & & & 3,0 \\
\hline 7 & Kesulitan pembuangan limbah cair & 15,09 & 5 & 0,755 & 1,2 & 0,2 & 0,9 & \\
\hline 8 & $\begin{array}{l}\text { Industri skala kecil dengan teknologi } \\
\text { terbatas }\end{array}$ & 9,43 & 5 & 0,472 & 2,8 & 0,3 & 0,7 & \\
\hline 9 & $\begin{array}{l}\text { Teknologi prosesing pati kurang dikuasai } \\
\text { oleh industri }\end{array}$ & 7,55 & 5 & 0,377 & 2,2 & 0,2 & 0,5 & \\
\hline 10 & Keterbatasan modal & 7,55 & 5 & 0,377 & 2,6 & 0,2 & 0,6 & \\
\hline \multirow[t]{2}{*}{11} & Kemampuan manajerial kurang & 5,66 & 4 & 0,226 & 1,8 & 0,1 & 0,3 & \\
\hline & Opportunities (O) & & & & & & & 2,5 \\
\hline 12 & Pangsa pasar luas & 13 & 5 & 0,65 & 2,1 & 0,3 & 0,9 & \\
\hline 13 & Permintaan besar & 14 & 4 & 0,56 & 2,7 & 0,4 & 0,9 & \\
\hline 14 & Dukungan pemda (mesin) & 4 & 3 & 0,12 & 2,1 & 0,1 & 0,2 & \\
\hline 15 & $\begin{array}{l}\text { Tambahan pendapatan produk ikutan dan } \\
\text { limbah (gamblong, kulit, bonggol, cair) }\end{array}$ & 2 & 4 & 0,08 & 2,5 & 0,0 & 0,1 & \\
\hline \multirow[t]{2}{*}{16} & $\begin{array}{l}\text { Terbuka kemitraan bagi bioindustri } \\
\text { berbahan baku ubikayu }\end{array}$ & 5 & 4 & 0,2 & 1,9 & 0,1 & 0,3 & \\
\hline & Threats $(T)$ & & & & & & & 4,3 \\
\hline 17 & Kontinuitas bahan baku & 12 & 5 & 0,6 & 3,4 & 0,4 & 1,0 & \\
\hline
\end{tabular}




\begin{tabular}{|c|c|c|c|c|c|c|}
\hline 18 & Persaingan antar industri ketat & 7 & 4 & 0,28 & 2,6 & 0,2 \\
\hline 19 & Harga bahan baku fluktuatif & 11 & 4 & 0,44 & 2,8 & 0,3 \\
\hline 20 & $\begin{array}{l}\text { Kualitas (rendemen) bahan baku tidak } \\
\text { stabil }\end{array}$ & 10 & 4 & 0,4 & 2,5 & 0,3 \\
\hline 21 & Kondisi cuaca (iklim) kurang mendukung & 6 & 3 & 0,18 & 1,4 & 0,1 \\
\hline 22 & Adanya pati impor & 8 & 4 & 0,32 & 2,4 & 0,2 \\
\hline 23 & Pembayaran tertunda (non cash and carry) & 0 & 3 & 0 & 1,2 & 0,0 \\
\hline 24 & Dinamika selera konsumen & 2 & 5 & 0,1 & 1,9 & 0,0 \\
\hline 25 & Birokrasi pengadaan modal kerja (skim) & 1 & 3 & 0,03 & 1,4 & 0,0 \\
\hline
\end{tabular}

Keterangan: Nilai 5 = sangat terkait; Nilai 4 = terkait; Nilai 3 = cukup terkait; Nilai 2 = kurang terkait; Nilai 1 = sangat kurang terkait

$\mathrm{BF}=$ Bobot faktor; ND $=$ Nilai dasar $\mathrm{NDB}=$ Nilai Dasar Berbobot $=(\mathrm{BF} / 100) \mathrm{x} \mathrm{ND}$

NRK $=$ Nilai Rata-rata Keterkaitan $=$ Nilai Keterkaitan $/ 17$

$\mathrm{NBK}=$ Nilai Bobot Keterkaitan $=(\mathrm{BF} / 100) \times \mathrm{NRK} ; \mathrm{TNB}=$ Total Nilai Bobot $=\mathrm{NDB}+\mathrm{NBK}$

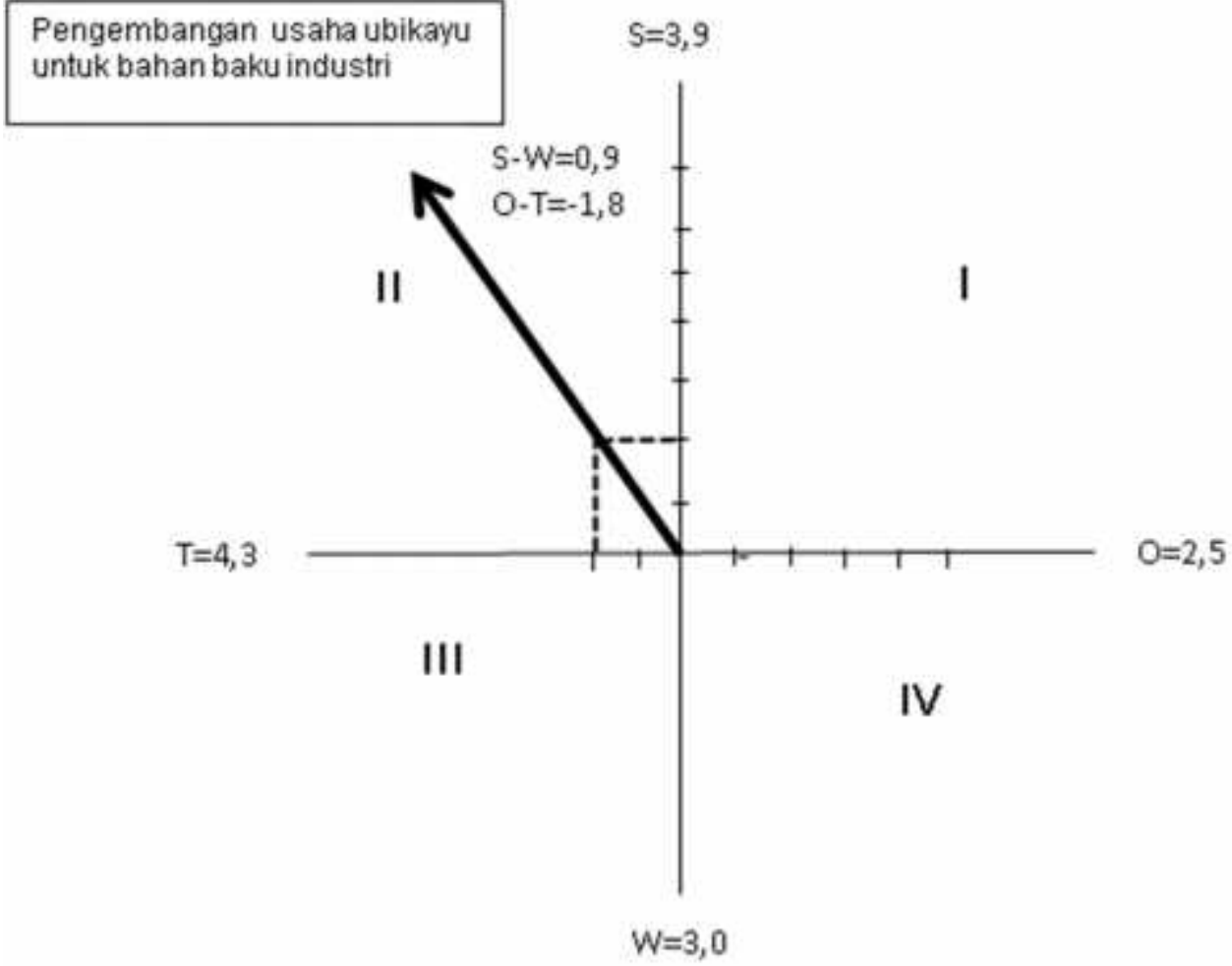

Gambar 1. Peta Kekuatan Pengembangan Ubikayu

Berdasarkan peta pengembangan ubikayu, maka strategi yang bisa dimunculkan adalah strategi berdasar dominasi komponen faktor kekuatan (S) dan faktor ancaman $(\mathrm{T})$ atau strategi $\mathrm{S}-\mathrm{T}$. Strategi yang sesuai adalah penggunaan teknologi baru varietas dan teknik budidaya pengaturan tanam. Dengan strategi tersebut, faktor ancaman pengem-bangan ubikayu dapat diantisipasi dengan faktor kekuatan yang dimiliki. Beragam varietas ubikayu telah tersedia sesuai peruntukan produk atau utilisasinya dan disertai teknologi pola pengaturan tanam ubikayu sehinggat terhindar dari terputusnya pasokan bahan baku karena musim penanaman. 


\section{Potensi Ekonomi Produk Samping}

Potensi nilai ekonomi limbah ubikayu untuk tujuan bioindustri mengacu pada definisi Suparmoko dan Maria (2000), Pearce dan Turner, 1991; Munasinghe, 1993; Pearce dan Moran, 1994) secara rinci disajikan di Tabel 2.

Perhitungan nilai ekonomi ubikayu didasarkan pada hasil prosesing di hulu (on farm) sampai produk hilir (produk perantara/jadi) dengan satuan perhitungan hasil ubikayu per ha. Valuasi ekonomi pada tingkat usahatani yaitu nilai penggunaan langsung yang dicerminkan dengan besarnya keuntungan per ha dan nilai penggunaan tidak langsung didekati dengan produk samping biomassa berupa daun dan batang. Harga daun ubikayu 1 ikat dengan berat $70 \mathrm{~kg}$ sebesar $\mathrm{Rp}$ 12.000,-. Batang untuk bibit Rp 10.000/15 biji. Harga kulit ubikayu Rp $10.000 /$ karung=25 kg. Bonggol (ujung umbi) dijadikan gaplek harga Rp 1300/kg. Limbah tapioka (gamblong) harga $\mathrm{Rp} \mathrm{35.000/zak}=65 \mathrm{~kg}$.Potensi nilai ekonomi usahatani ubikayu sebesar Rp 71.790.000,- dengan manfaat ekonomi tidak langsung sebesar Rp 20.698.00 atau 29,7\% dari manfaat ekonomi yang langsung diterima petani.

Tabel 2. Potensi Nilai Ekonomi Ubikayu Tujuan Bioindustri

\begin{tabular}{|c|c|c|c|c|c|c|}
\hline \multirow[b]{2}{*}{ Kategori } & \multicolumn{3}{|c|}{ Nilai penggunaan per ha (Rp) } & \multicolumn{2}{|c|}{ Nilai Intrinsik } & \multirow[b]{2}{*}{$\begin{array}{c}\text { Total } \\
\text { (Rp/ha) }\end{array}$} \\
\hline & $\begin{array}{c}\text { Nilai } \\
\text { penggunaan } \\
\text { langsung }\end{array}$ & $\begin{array}{c}\text { Nilai } \\
\text { penggunaan } \\
\text { tidak } \\
\text { langsung }\end{array}$ & $\begin{array}{l}\text { Nilai } \\
\text { pilihan }\end{array}$ & $\begin{array}{c}\text { Nilai } \\
\text { keberadaan }\end{array}$ & $\begin{array}{l}\text { Nilai warisan } \\
\text { / kebanggaan }\end{array}$ & \\
\hline 1. Usahatani & 51.100 .000 & 7.698 .000 & $\mathrm{X}$ & - & - & 58.798 .000 \\
\hline - daun & & 1.028 .000 & $\mathrm{X}$ & & & \\
\hline - batang & & 6.670 .000 & $\mathrm{X}$ & & & \\
\hline 2. Bahan & & & & - & - & \\
\hline baku pangan & $\mathrm{X}$ & 5.700 .000 & $\mathrm{X}$ & & & 5.700 .000 \\
\hline - kulit & $\mathrm{X}$ & 500.000 & $\mathrm{X}$ & & & \\
\hline ubikayu & $\mathrm{X}$ & 5.200 .000 & $\mathrm{X}$ & & & \\
\hline - bonggol & & & & & & \\
\hline 3. Bahan & & & $\mathrm{X}$ & & & \\
\hline baku pakan & & & $\mathrm{X}$ & Tidak & & \\
\hline - pupuk & & & $\mathrm{X}$ & terdeteksi & & \\
\hline - biogas & & & & - & - & \\
\hline 4. Bahan & & 7.300 .000 & $\mathrm{X}$ & & & 7.300 .000 \\
\hline baku industri & & 300.000 & $\mathrm{X}$ & & & \\
\hline - kulit & & $\mathrm{X}$ & $\mathrm{X}$ & & & \\
\hline - bonggol & & 7.000 .000 & $\mathrm{X}$ & & & \\
\hline - gamblong & & $\mathrm{X}$ & $\mathrm{X}$ & & & \\
\hline - limbah cair & & & & & & \\
\hline Total & 51.100 .000 & 20.698 .000 & & & & 71.798 .000 \\
\hline
\end{tabular}

Sumber: Data primer, 2019

Potensi nilai ekonomi usahatani ubikayu sebesar Rp 71.798.000,- memiliki manfaat ekonomi tidak langsung sebesar Rp 20.698.000 atau 29,7\% dari manfaat ekonomi yang langsung diterima petani. 


\section{Implikasi Kebijakan}

Salah satu komoditas pangan yang berpotensi untuk dikembangkan di Indonesia khususnya di Pulau Jawa adalah ubikayu. Komoditas ini dapat digunakan sebagai sumber pakan potensial karena hampir semua bagian tanaman maupun limbah selama ini dibuang, ternyata sangat baik untuk bahan pakan.

Untuk menuju sistem usahatani ubikayu berbasis bioindustri, harus disiapkan teknologi pendukung. Sistem yang dimaksudkan adalah kesatuan usaha yang mencakup komponen-komponen yang berkaitan satu sama lainnya untuk mencapai tujuan dalam lingkungan yang kompleks. Pendekatan sistem yang diperlukan meliputi tahapan analisis kebutuhan, formulasi masalah, identifikasi sistem, simulasi sistem, dan validasi sistem. Sistem usahatani ubikayu yang dibangun perlu ditindak lanjuti dengan uji sensitivitas untuk mengetahui batasbatas sejauh mana sistem tersebut masih bisa mencapai tujuan yang telah ditentukan (Hartrisari, 2007; Eriyatno, 2003).

Berdasarkan SIPP 2013-2045 (Kementan 2013) teknologi yang dipersiapkan antara lain: Pertama, teknologi tanaman ubikayu integrasi dengan ternak yaitu teknologi yang menghasilkan biomassa tinggi untuk kebutuhan pakan. Permasalahan kompetisi terhadap sumberdaya alam yang mungkin timbul dari intensifikasi pemanfaatan lahan dapat teratasi dengan cara integrasi seperti ini. Cara ini mampu menyediakan kebutuhan biomassa untuk kebutuhan pangan, pakan, dan juga sebagai bahan baku industri. Kedua, teknologi tanaman ubikayu integrasi dengan energi yaitu teknologi yang menghasilkan biomassa tinggi untuk kebutuhan energi. Usahatani ubikayu dalam hal ini diutamakan memanfaatkan lahan marjinal dan sub-optimal. Optimasi pemanfaatan lahan tersebut meningkatkan produktivitas biomassa tanaman ubikayu misalnya sebagai lahan penyedia bahan baku bioindustri non pangan khususnya bioindustri.

Banyak teknologi ubikayu yang tersedia untuk tujuan industri. Namun teknologi tersebut belum dimanfaatkan oleh pengguna (petani) yang sesuai dengan keinginan industri. Disamping itu, tidak banyak informasi mengenai preferensi biomassa dari tanaman ubikayu yang dibutuhkan sebagai bahan baku oleh industri. Dengan demikian, diperlukan informasi mengenai potensi dan permasalahan tanaman ubikayu yang terkait dengan bioindustri.

Ubikayu merupakan salah satu komoditas pangan yang memiliki potensi untuk dikembangkan menjadi bioindustri. Biomassa dari ubikayu selain digunakan untuk pangan dan pakan, juga berpotensi untuk diubah menjadi sumber energi terbarukan (bahan bakar cair biofuel).

Peluang pengembangan bioindustri dari ubikayu cukup besar karena berbagai karakteristik yang dimiliki komoditas ini. Pertama, ubikayu sudah sangat dikenal oleh petani di Indonesia. Kedua, ubikayu dapat ditanam dengan mudah di seluruh kawasan Indonesia meski tingkat kesuburan tanahnya rendah. Ketiga, ubikayu merupakan tanaman yang sangat fleksibel dalam usahatani dan umur panen, serta tahan terhadap cekaman biotik dan abiotik. Keempat, ubikayu dapat berproduksi dengan baik di lingkungan sub-optimal dibandingkan tanaman lainnya. Kelima, perkembangan kemajuan teknologi pertanian saat ini memungkinkan produktivitas ubikayu meningkat hingga 100\% dari rata-rata produktivitas di tingkat petani yang ada. 


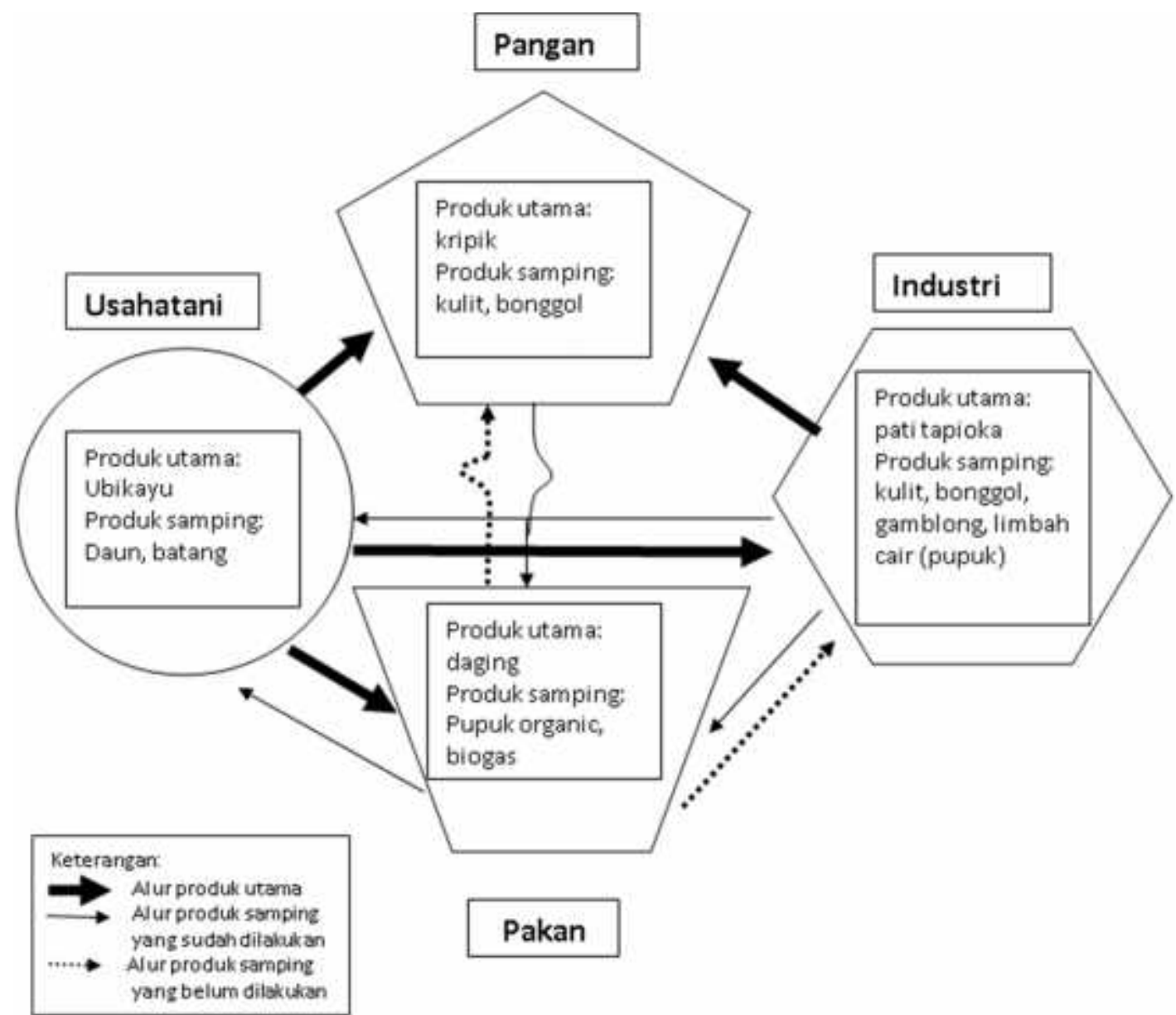

Gambar 2. Pola Integrasi Tanaman dan Ternak

Perpres No. 5 tahun 2006 tentang pengembangan sumber energi terbarukan dari biomasa (biofuel) mencakup biodiesel, bioetanol dan bio-oil sebagai substitusi BBM merupakan peluang besar bagi ubikayu sebagai penunjang bahan baku untuk bioetanol. Namun, pengembangan industri pangan besar dari bahan baku ubikayu berlangsung lambat. Seperti yang dikemukakan oleh Husodo (2006), bahwa teknologi pengolahan tepung dan bahan yang dapat diproduksi sendiri seperti tepung tapioka, tepung beras, tepung jagung, tepung sagu belum berkembang dengan baik sebagai bahan baku roti pengganti gandum. Oleh karenanya, sebagian besar industri makanan tetap menjadikan tepung terigu sebagai bahan baku.

Sistem bioindustri ubikayu menitikberatkan kepada penggunaan (utilisasi) produk nantinya. Utilisasi produk diimplementasikan kedalam permintaan pasar, sehingga preferensi petani bergantung kepada permintaan pasar. Kebutuhan untuk pangan (industri pangan) membutuhkan jenis ubikayu dengan rasa enak terutama untuk produk-produk kripik dan yang disukai berwarna daging umbi kuning pada jenis produk tape tertentu.

\section{KESIMPULAN DAN SARAN}

Ubikayu memiliki potensi yang semakin penting di masa mendatang terutama sebagai bahan baku industri pangan dan pakan. Dalam jangka pendek strategi pengembangan ubikayu sebagai bahan baku industri yang dilakukan adalah 
penggunaan teknologi baru berupa varietas dan teknik budidaya pengaturan tanam. Potensi nilai ekonomi ubikayu relatif tinggi ditinjau dari aspek usahatani, bahan baku pangan, pakan dan industri.

Potensi nilai ekonomi dari ubaikayu selain yang langsung dapat dimanfaatkan hasilnya (utama) juga ada nilai produk samping yang selama ini terabaikan dengan besaran nilai kuantitatif sepertiga dari nilai hasil utama ubikayu $(29,7 \%)$. Potensi produk samping ini belum digunakan secara optimal dan merupakan nilai bioekonomi berupa biomassa yang dapat menunjang integrasi pertanian di masa mendatang.

\section{DAFTAR PUSTAKA}

Beebe, J. 2014. Rapid Qualitative Inquiry. A Field Guide to Team Based Assessment. Rowman \& Littlefield. Lanham Maryland.

Damardjati, D. S. 2011. Menuju Industri Pertanian Bernilai Tambah dan Berorientasi

Pasar. http://www.foodreview.biz/preview.php?view2\&id=55720 . Download: 13 September 2011.

Eriyatno. 2003. Ilmu Sistem: Meningkatkan Mutu dan Efektivitas Managemen. IPB Press. Bogor.

Fauquet, C. 2016. The First World Congress on Root and Tuber Crops (Kongres Dunia Pertama tentang Tanaman Akar dan Umbi) yang berlangsung di Nanning, Guangxi, Tiongkok, 18-22 Januari 2016. Download: 27 Juli 2018.

Hartrisari. 2007. Sistem Dinamik. Konsep Sistem dan Pemodelan untuk Industri dan Lingkungan. Institut Pertanian Bogor. SEAMEO BIOTROP. Bogor.

Husodo S. 2006. Pangan dan Masa Depan Bangsa. Dalam: Ketut Puspanji, Wayan Rusastra, Dwi Praptomo, Sudi Mardianto, Suwaji, Dahlannudi, dan Wirajaswadi (Eds.). Pemasyarakatan Inovasi Teknologi Pertanian sebagai Penggerak Ketahanan Pangan Nasional. Balai Besar Pengkajian dan Pengembangan Pertanian Bogor.

Jarvis, A.; Ramirez-Villegas, J.; Campo, B.V.H. and Navarro, C. 2012. Is Cassava the Answer to African Climate Change Adaptation?. Available from: https://www.researchgate.net/publication/234076183_Is_Cassava_the_Ans wer_to_African_Climate_Change_Adaptation [accessed Jul 20 2018]. Article (PDF Available) in Tropical Plant Biology 5(1):9-29 · March 2012

Matthew, F. and Aung, M.T. 2018. Bioeconomy in Thailand: a case study. Stockholm Environment Institute. Stockholm Sweden.

Munasinghe, M. 1993. Environmental Economics and Sustainable Development. World Bank Environment Paper Number 3. The World Bank. Washington D.C.

Mupakati T and Vincent I. Tanyanyiwa. 2017. Cassava production as a climate change adaptation strategy in Chilonga Ward, Chiredzi District, Zimbabwe. Jamba. 2017; 9(1): 348. 
Sunanto dan Nasrullah. 2012. Kajian Model Pertanian Zero Waste Dengan Pendekatan Sistem Integrasi Tanaman Jagung-Ternak Sapi di Sulawesi Selatan. Prosiding InsINas. http:insentif.ristek.go.id/PROSIDING2012/filePG-Word_38.pd. Diunduh 3 Pebruari 2014.

Chuzaemi, S. 2002. Arah dan Sasaran Penelitian Nutrisi Sapi Potong Lokalit Sapi Potong. Puslitbang Peternakan. Bogor.

Kementan. 2013. Statistik Pertanian.

Pearce, D.W dan Turner, K. 1991. Economics of Natural Resources and The Environment Harvester Wheatsheaf.

Pearce, D.W dan D. Moran, 1994. The Economic Value of Biodiversity. IUNC. Earthscan Publication, London.

Pudjiastuti, A.Q.; Anindita, R.; Hanani, N.; Kaluge, D. 2013. Effects of Sugar Price Increase in Indonesia. Oeconomica. Vol. 58 Issue 1 pp. 28-39. Babes-Bolyai University.

Pudjiastuti, A.Q. 2014. Perubahan Neraca Perdagangan Indonesia sebagai Akibat Penghapusan Tarif Impor Gula. Agriekonomika. Vol. 3 No. 2 hal. 106-116. Universitas Trunojoyo Madura.

Pudjiastuti, A.Q. and Kembauw, E. 2018. Sugar Price Policy and Indonesia's Trade Balance. Journal of Advanced Research in Law and Economics. Vol. 8 Issue 30 pp. 2540-2548. Asers Publishing.

Rangkuti, F. 2001. Analisis SWOT: Teknik Membedah Kasus Bisnis. PT. Gramedia Pustaka Utama. Jakarta.

Rostini, T. and Biyatmoko, D. 2019. Performance of kacang goats fed with complete wafered forage based on Palm plantation waste. Pakistan Journal of Nutrition. Vol 18 No 6: 514-518.

Suci, D.H. 2007. Kebon Singkong Medco di Lampung (Reportase). Post info tanggal 19 November 2007. http://sucidh.wordpress.com/2007/11/19/kebonsingkong-medco-di-lampung/. Diunduh 3 Pebruari 2014.

Sunanto dan Nasrullah. 2012. Kajian Model Pertanian Zero Waste Dengan Pendekatan Sistem Integrasi Tanaman Jagung-Ternak Sapi di Sulawesi Selatan. Prosiding InsINas. http: insentif.ristek.go.id/PROSIDING2012/filePG-Word_38.pd. Diunduh 3 Pebruari 2014.

Suparmoko dan Maria. 2000. Ekonomi Lingkungan. BPFE. Yogyakarta. 